\title{
Improvement of Bonding Strength of Horizontal Twin-Roll Cast Steel/Aluminum Clad Sheet by Electromagnetic Fields
}

\author{
Gang Chen ${ }^{1} \cdot$ Jin-Tao $\mathrm{Li}^{1,2} \cdot$ Guang-Ming $\mathrm{Xu}^{1}$
}

Received: 10 February 2017/Revised: 26 May 2017/Published online: 9 September 2017

(c) The Chinese Society for Metals and Springer-Verlag GmbH Germany 2017

\begin{abstract}
Electromagnetic field is an available online method to increase bonding strength of clad sheet manufactured by horizontal twin-roll casting (HTRC). In this paper, an electric current pulse (ECP) and a complex field (static magnetic field (SMF) together with ECP) are exerted during HTRC of steel/aluminum clad sheet. The produced clad sheet has good appearance, and no visible defects exist at the bonding interface. The inter-diffusion zone at Fe/Al interface in ECP and $\mathrm{SMF}+\mathrm{ECP}$ sheets is 3 and $4 \mu \mathrm{m}$, respectively, and the latter increases slightly compared with that in non-field sheet. The average peel strengths (APS) of ECP and SMF+ECP sheet are 14 and $21 \mathrm{~N} / \mathrm{mm}$, respectively, which increase by 2 and $9 \mathrm{~N} / \mathrm{mm}$ compared with $12 \mathrm{~N} / \mathrm{mm}$ of non-field sheet. The APS increment in SMF+ECP sheet is resulted from the increment of interface bonding spots and the enhancement of inter-diffusion zone width.
\end{abstract}

KEY WORDS: Clad sheet; Twin-roll casting; Electromagnetic field; Bonding strength

\section{Introduction}

Twin-roll casting (TRC) is an emerging technology for producing metal sheets, which provides a relatively high solidification rate $\left(10^{2}-10^{3} \mathrm{~K} / \mathrm{s}\right)[1-3]$. During TRC, molten metal is poured into the gap between two water-cooled rotating rolls, which are designed to realize the simultaneous employment of casting and hot rolling $[4,5]$. This advantage has the potential of avoiding subsequent rolling. Based on above characteristics, TRC technique has also been utilized to fabricate clad metallic sheets. Haga and

Available online at http://link.springer.com/journal/40195

Guang-Ming Xu

xu_gm@epm.neu.edu.cn

1 Key Laboratory of Electromagnetic Processing of Materials (Ministry of Education), Northeastern University, Shenyang 110819, China

2 School of Mechanical, Materials and Mechatronic Engineering, University of Wollongong, Wollongong, NSW 2500, Australia
Suzuki [6] produced Al-12\%Si/AA1050 clad sheets using horizontal twin-roll casting (HTRC) technique. The clad sheets had a clear interface, and the layers were bonded so strongly that the sheet did not peel off at the interface after bending and tensile test. Bae et al. [7] produced $\mathrm{Al} / \mathrm{Mg}$ clad sheet using HTRC in order to enhance the corrosion resistance of $\mathrm{Mg}$ sheets. The bonding was sound and no crack was found at the interface after rolling and bending. Vidoni et al. [8] produced clad strips by vertical twin-roll casting (VTRC) technique with a combination of austenitic stainless steel and carbon steel. The interface appearance of the clad strip varied from region to region due to nonuniform local re-melting of the steel strips and as a result, local separation between the two layers was observed. Grydin et al. [9] experimentally fabricated a steel/aluminum clad sheet by VTRC. An austenitic steel strip was used as the clad strip fed through the gap between the roll and the nozzle. Commercially pure aluminum melt was poured into the nozzle to form the base strip. Subsequent deep drawing and rolling of the clad sheet showed that the bonding strength was high enough and no delamination occurred. 
In TRC of clad sheets, process parameters such as casting speed and pouring temperature decide both the bonding strength and the process stability and sheet shape. This means that the bonding strength cannot be enhanced further except that extra online methods can be used. Electromagnetic field is a certificated and effective means for improving solidification structure and mechanical properties of metals. Liao et al. [10] exerted electric current pulse (ECP) on the solidification process of pure aluminum, and the results showed that the solidification structure can be refined during the nucleation of the melt. Ma et al. [11] also exerted ECP on the solidification process of pure aluminum, and the same results were obtained. Rabiger et al. [12] considered the impact of ECP on the solidification of Al-7 wt\% Si alloys for the configuration of two parallel electrodes immersed from the free surface into the solidifying alloy. The application of ECP at frequencies up to $200 \mathrm{~Hz}$ led to the formation of refined equiaxed grain structures. Song et al. [13] investigated the effect of ECP on the interface morphology of $\mathrm{Al}-4.5 \mathrm{wt} \% \mathrm{Cu}$ alloy under the directional solidification conditions. Experimental results suggested that ECP can make the convex interface flat, decrease the primary spacing and the depth of mushy zone, and delay the planar/cellular transition. Zhang et al. [14] analyzed the influence of an ECP on the microstructure of an Al-Si eutectic alloy during directional solidification. Application of ECP can increase the number and area percentage of the complex regular structure. Su et al. [15] simultaneously imposed static magnetic field (SMF) and ECP on the TRC process of 7075 aluminum alloy sheets. The experimental results showed that complex field can effectively enhance the solute solid solution, eliminate segregation and refine the microstructure.

Recently, the authors studied the bonding strength of steel/aluminum clad sheets subjected to non-field HTRC, subsequent annealing and rolling processes [16]. In this study, we further studied the effect of ECP and SMF+ECP fields on the interface bonding of steel/aluminum clad sheets during HTRC. The function mechanism of electromagnetic fields on the bonding interface during HTRC was discussed.

\section{Experimental}

The steel/aluminum clad sheets were fabricated on a horizontal twin-roll caster with an ECP or a SMF+ECP field. The caster has a roll diameter and width of $500 \mathrm{~mm}$. The roll gap was set to $3.8 \mathrm{~mm}$, which was measured by rolling a 10 -mm-wide and 8-mm-thick pure $\mathrm{Al}$ stick and taking the after-rolling thickness as the roll gap value. The ferrite stainless steel 409L was used as cladding strip, with $0.25 \mathrm{~mm}$ in thickness and $210 \mathrm{~mm}$ in width. A self-made pinch roll was used to exert a tension on the steel strip. The ECP was generated with a pulse stabilized power supply. The peak value, frequency and duty ratio were set to $600 \mathrm{~A}, 20 \mathrm{~Hz}$ and 15\%, respectively. One end of the ECP wire was inserted into melt, and the other end was pressed on the clad sheet surface to form loop. Two homemade electromagnetic generators were used to generate SMF. One was put under the nozzle and the other under clad sheet close to roll bite at the exit side. The vertical magnetic flux density applied in the cast-rolling zone was $45 \mathrm{mT}$. Schematic diagram of the device is shown in Fig. 1a. A detailed diagram of the cast-rolling zone is shown in Fig. 1b. Directions of the SMF and ECP exerted in the cast-rolling zone are shown schematically in Fig. 1c with the ECP waveform on the top right corner. AA1100 alloy was used to form the base strip. Chemical compositions of the materials are listed in Table 1. Before casting, a commercial-purity aluminum ingot was melted in a resistance furnace. When the melt temperature reached $750{ }^{\circ} \mathrm{C}, \mathrm{Fe}$ and $\mathrm{Si}$ master alloys were added into it. Then the melt was hold at the temperature for $2 \mathrm{~h}$, after which the temperature was decreased to $700{ }^{\circ} \mathrm{C}$. The casting speed was set to $1.5 \mathrm{~m} / \mathrm{min}$ at the beginning and reduced to $1.25 \mathrm{~m} / \mathrm{min}$ after a sheet length of $1 \mathrm{~m}$. ECP was applied when the non-field sheet had a length of $1 \mathrm{~m}$, and SMF was exerted simultaneously after an ECP sheet length of $1 \mathrm{~m}$. The length of the ECP+SMF sheet was also $1 \mathrm{~m}$, after which the casting was stopped. The cross section of the steel/aluminum clad sheet was $4.3 \mathrm{~mm} \times 210 \mathrm{~mm}$. It has to be pointed out that during casting, the separating force would exceed the maximum roll pressure force and as a result, together with the elastic deformation, the sheet thickness is larger than the roll gap.

It has to be pointed out that the higher initial casting speed was used to heat the cold nozzle and help to build the stable casting more quickly. As the runner inside the nozzle is relatively small $(250 \mathrm{~mm} \times 6 \mathrm{~mm} \times 5 \mathrm{~mm})$ and the area between runner exit and nozzle exit is only $0.012 \mathrm{~m}^{2}$, after the first $1 \mathrm{~m}$, the nozzle temperature had reached stable value. Moreover, the thermal conductivity of the nozzle is only $0.12 \mathrm{~W} /(\mathrm{m} \mathrm{K})$, which also benefits the quick building of the stability. Another reason for the quick building of process stability is that the roll shell is rather thick $(40 \mathrm{~mm})$ and the casting speed was low. That means the roll surface had enough time to restore to room temperature before the next touching with the melt. This has been verified by the simulation of the stable temperature field of roll shells during cladding TRC as shown in Fig. 2. Thus the effect of fluctuations of casting speed and melt temperature on the bonding strength can be excluded.

Metallographic study was conducted on grinded and polished samples at rolling direction (RD)-normal direction (ND) surfaces. The micro-topography at the bonding 

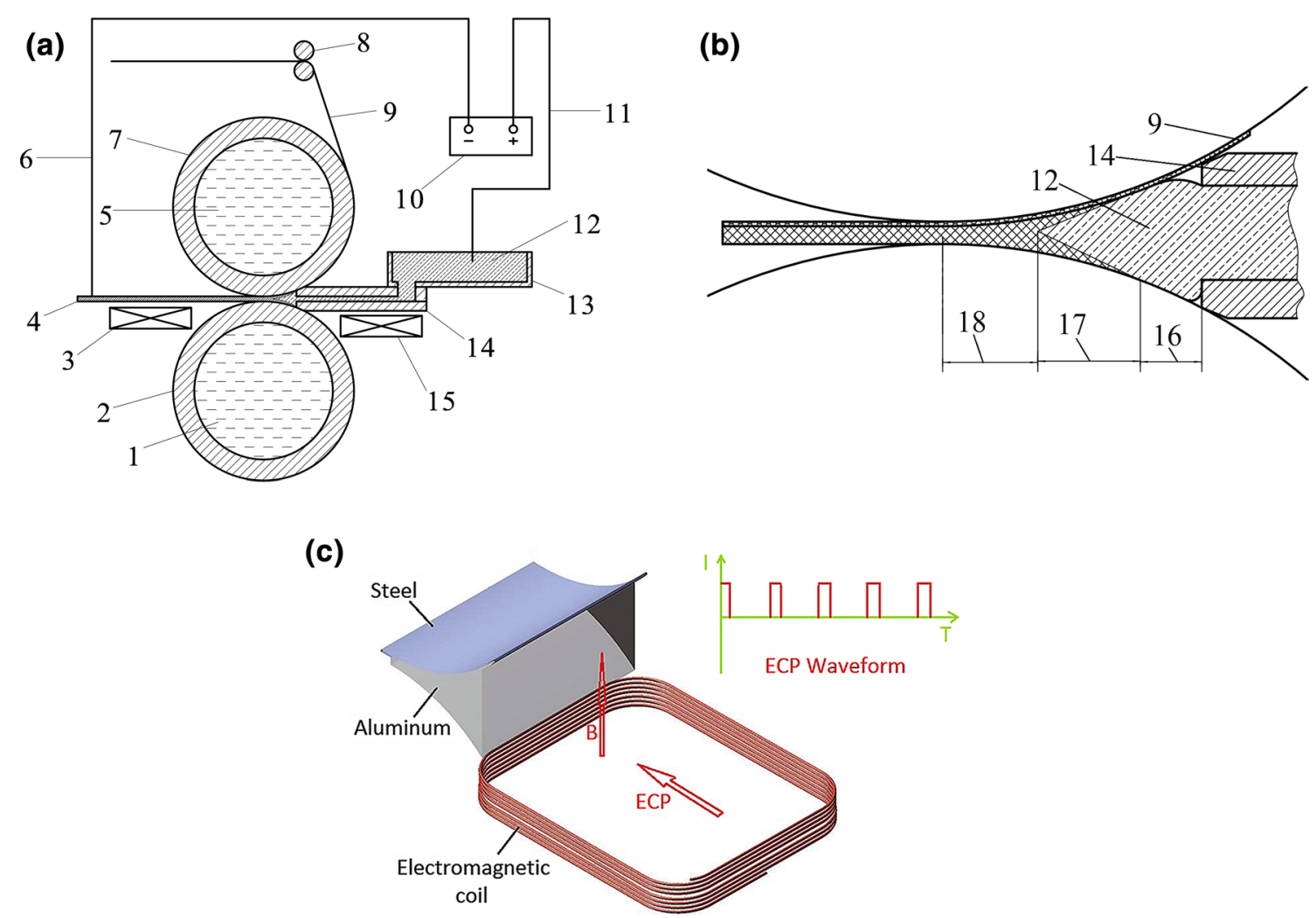

Fig. 1 Schematic diagram of TRC: a the device, $\mathbf{b}$ an enlarged image of cast-rolling zone, $\mathbf{c}$ directions of ECP and SMF. 1 and 5 cooling water; 2 lower roll; 3 and 15 electromagnetic coil; 4 clad sheet; 6 and 11 wire; 7 upper roll; 8 steel strip pinch roll; 9 steel strip; 10 pulsed power supply; 12 aluminum melt; 13 sluice; 14 nozzle; 16 liquid zone; 17 liquid-solid coexisted zone; 18 solid zone

Table 1 Chemical compositions of stainless steel and AA1100 alloy (wt $\%)$

\begin{tabular}{lllllll}
\hline Material & $\mathrm{Fe}$ & $\mathrm{Cr}$ & $\mathrm{Si}$ & $\mathrm{Al}$ & $\mathrm{Ti}$ & $\mathrm{Mg}$ \\
\hline Stainless steel & 86.292 & 11.874 & 1.145 & 0.21 & 0.13 & 0.128 \\
AA1100 & 0.256 & - & 0.468 & 99.0 & - & - \\
\hline
\end{tabular}

interface was studied on a Leica DMR optical microscopy $(\mathrm{OM})$. The element diffusion across the bonding interface was investigated using a JEOL JXA-8530F electron probe micro-analyzer (EPMA). To test the bonding strength, T-type peeling test was carried out on a SHIMADZU AG$\mathrm{X}$ universal testing machine at a tensile speed of $10 \mathrm{~mm} /$ min according to ASTM D1876-08. Peeling test samples with a size of $100 \times 10 \mathrm{~mm}$ were cut along the rolling direction. The testing method and calculation of peeling strength can be found elsewhere [16]. After peeling, the micro-topography of bonding surfaces was studied on a SHIMADZU SSX-550 scanning electron microscope (SEM) equipped with energy-dispersive spectrometer (EDS). It has to be pointed out that the testing samples were cut from the parts $30 \mathrm{~mm}$ away from the sheet side to assure the effectiveness of the fields.

\section{Results}

Figure 3 shows the non-field, ECP and SMF+ECP processed steel/aluminum clad sheets fabricated by HTRC. The clad sheet has a relatively good appearance without melt leakage at the sides. Some wrinkles appear on the surface of non-field and ECP sheets as shown in Fig. 3a, b, respectively. The SMF+ECP sheet shown in Fig. $3 c$ is very flat, and nearly no wrinkles appear on the surface. Compared with non-field clad sheet, ECP and SMF+ECP sheets have the similar shape and exerting external fields do not affect the process stability of TRC.

The micro-topographies of bonding interface in nonfield, ECP and SMF+ECP sheets are shown in Fig. 4a, b, $c$, respectively. Compared with that of non-field clad sheet [16], as shown in Fig. 4a, ECP and SMF+ECP eliminate 

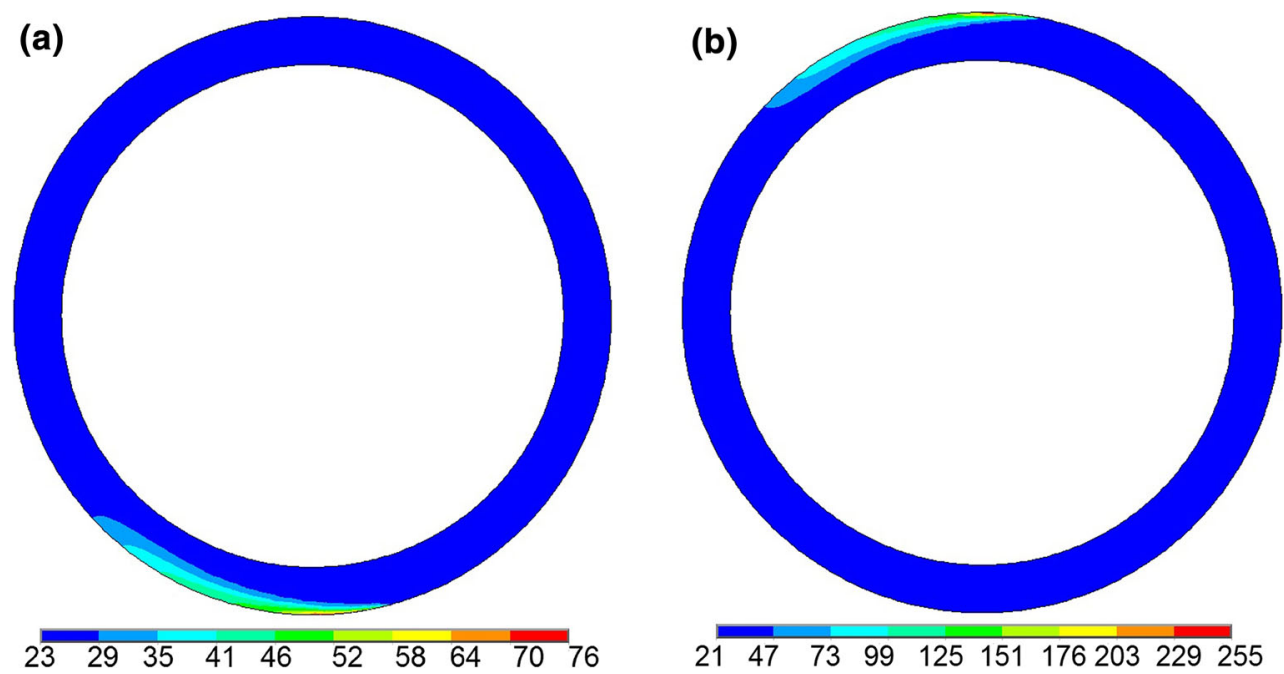

Fig. 2 Stable temperature field of roll during TRC for clad sheet, with casting speed of $1.25 \mathrm{~m} / \mathrm{min}$ and pouring temperature of $700{ }^{\circ} \mathrm{C}$ : a upper roll; b lower roll
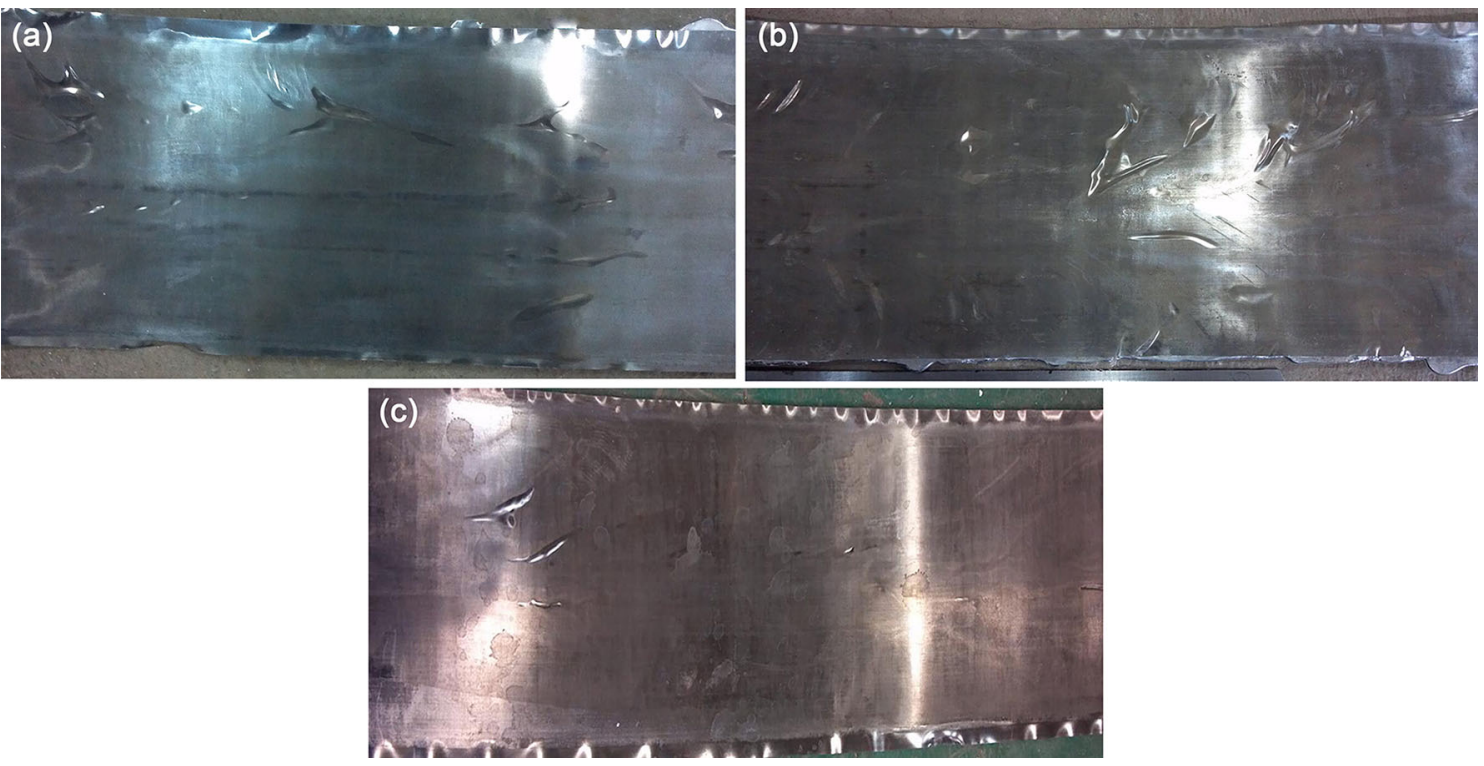

Fig. 3 a Non-field clad sheet, b ECP processed clad sheet, c SMF+ECP processed clad sheet

the residual voids. No visible defects can be seen at the interfaces in the ECP and SMF+ECP sheets, as shown in Fig. $4 b$, c.

The back-scattered images and corresponding line scanning positions across the interface are shown in Fig. 5. In the ECP clad sheet, a 3- $\mu \mathrm{m}$-wide inter-diffusion zone appears at the bonding interface, as indicated by the vertical lines in Fig. 5b1. In the SMF+ECP sheet, the interdiffusion zone slightly increases to $4 \mu \mathrm{m}$ as shown in Fig. 5c2. Compared with non-field (Fig. 5a2) [16] and ECP sheet (Fig. 5b2), the inter-diffusion zone increases slightly after applying SMF+ECP.

The peel strength curves of the steel/aluminum clad sheets are shown in Fig. 6. The dash lines in the figure show the average peel strength (APS). The APS of ECP and SMF+ECP clad sheets are about 14 and $21 \mathrm{~N} /$ $\mathrm{mm}$, respectively. Compared with $12 \mathrm{~N} / \mathrm{mm}$ of non-field sheet, the APS of ECP and SMF+ECP clad sheet increases by 2 and $9 \mathrm{~N} / \mathrm{mm}$, with an increase rate of 17 and $75 \%$, respectively. Notice that the peeling curves are with an apparent fluctuation, which is a typical characteristic as indicated in the work of Eizadjou et al. [17].

Aluminum surface morphologies of the non-field, ECP and SMF+ECP sheets after peeling are shown in Fig. 7a, b, c, respectively. It has to be pointed out that Fig. 7a has been published in Ref. [16]. It is obvious that more salients exist on the surface of ECP and SMF+ECP sheets compared with that of the non-field case. Besides the coarse 

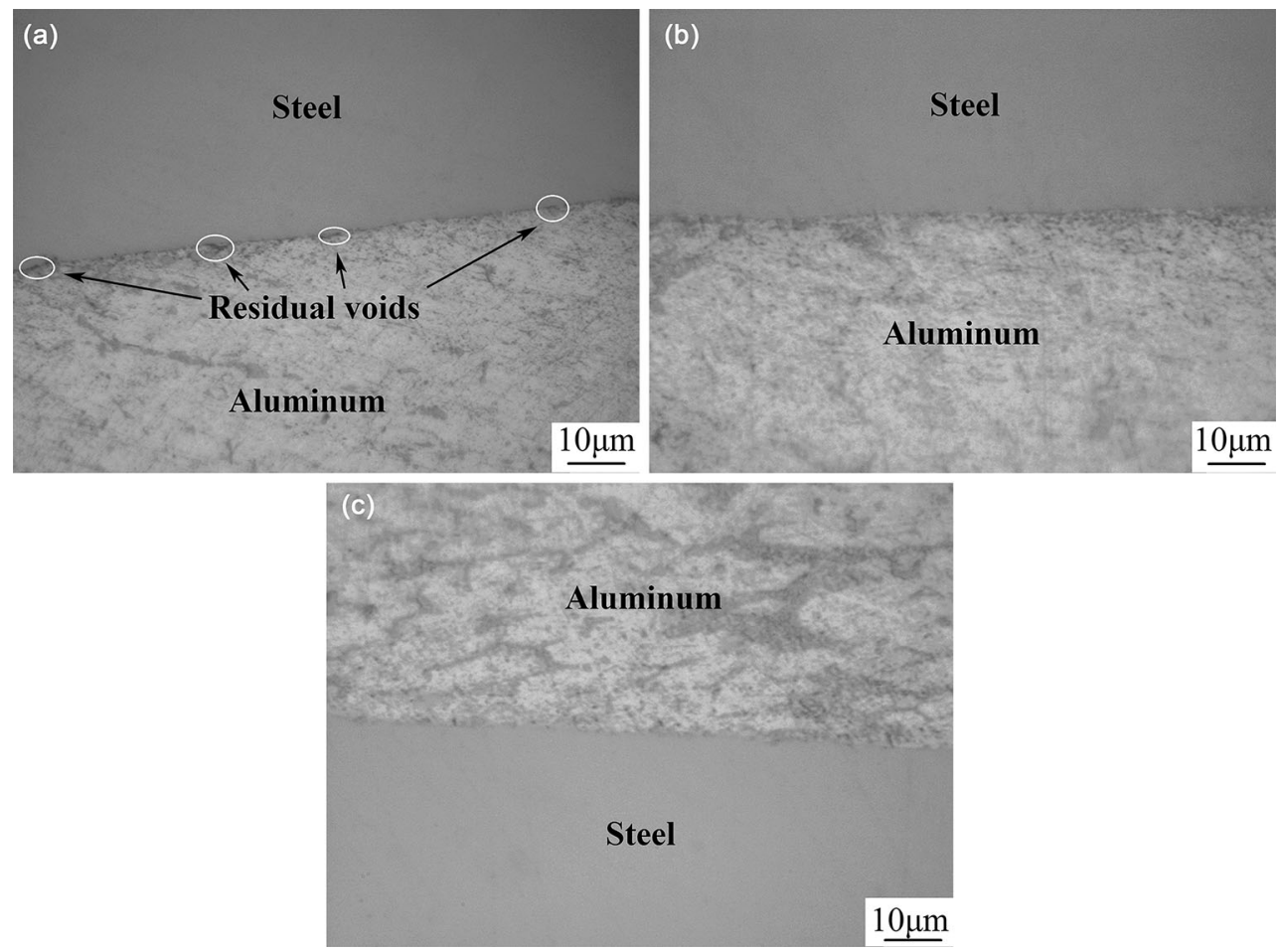

Fig. 4 Micro-topographies of steel/aluminum interface in a non-field [16], b ECP, c SMF+ECP clad sheets

salient, some small ones can also be observed after SMF+ECP treatment as shown in Fig. 7c. This indicates that ECP and SMF+ECP treatments cause more bonding zones and SMF+ECP treatment has more obvious effect.

\section{Discussion}

In the TRC process, the regions most influenced by the electromagnetic field should be the liquid and liquid-solid coexisted zone, where the solidification of the metal occurs. If no field is applied, except random thermal motion, every ion moves stably with the casting speed $\vec{v}$. When ECP is applied on the liquid and liquid-solid coexisted zone, a pulse magnetic field $\overrightarrow{B_{\mathrm{ECP}}}$ is induced and then furtherly a Lorentz force $\vec{f}=q \vec{v} \times \overrightarrow{B_{\mathrm{ECP}}}$ is generated. Here $q$ is the particle charge. The Lorentz force has an oscillatory surge on the molten metal, which results in an intensive strike on the steel surface. During nucleation, the nuclei created on the steel surface are broken off and fall into the melt under the pulse electromagnetic force. In other words, the nuclei will be dissociated on the steel surface by the Lorentz force if a solidification shell has not been formed on the steel surface. The dissociation of nuclei leaves the space for aluminum alloy melt to contact the steel surface. Also, the strike effect of the Lorentz force can reduce the temperature gradient. These behaviors can increase the contact point between aluminum melt and steel surface and result in generating more bonding points. This can be proved that more salients exist in aluminum surface of ECP clad sheet (Fig. 7b). Thereby, ECP increases the bonding strength. But TRC has high solidification rate, the nucleation time is very short, which limits the increase of bonding points and further limits the increase of bonding strength.

Simultaneous application of SMF $\overrightarrow{B_{\mathrm{SMF}}}$ and ECP with current density $\vec{J}$ on the cast-rolling zone results in the generation of an electromagnetic body force $\vec{F}=\vec{J} \times \overrightarrow{B_{\mathrm{SMF}}}$, with a frequency equal to that of the applied electric field and a direction perpendicular to the plane of the two fields. This force acts on the steel surface and cause a more intensive strike and a strong convection. At the same time, the Lorentz force generated by ECP also exists and acts on the steel surface. Compared with the electromagnetic body force, the Lorentz force is small. The strike effect generated by the electromagnetic body force can more intensively break off the nuclei. The convection can promote heat transfer and increase the fluidity of melt and result in the more uniform distribution of the temperature and solute concentration. These effects are very beneficial for increasing the contact point and generating more bonding points. Moreover, the inter-diffusion zone in SMF+ECP sheet is larger than that in the two other sheets as shown in Fig. 5. The reason for the bonding caused by the inter-diffusion zone is the solid solution strengthening 

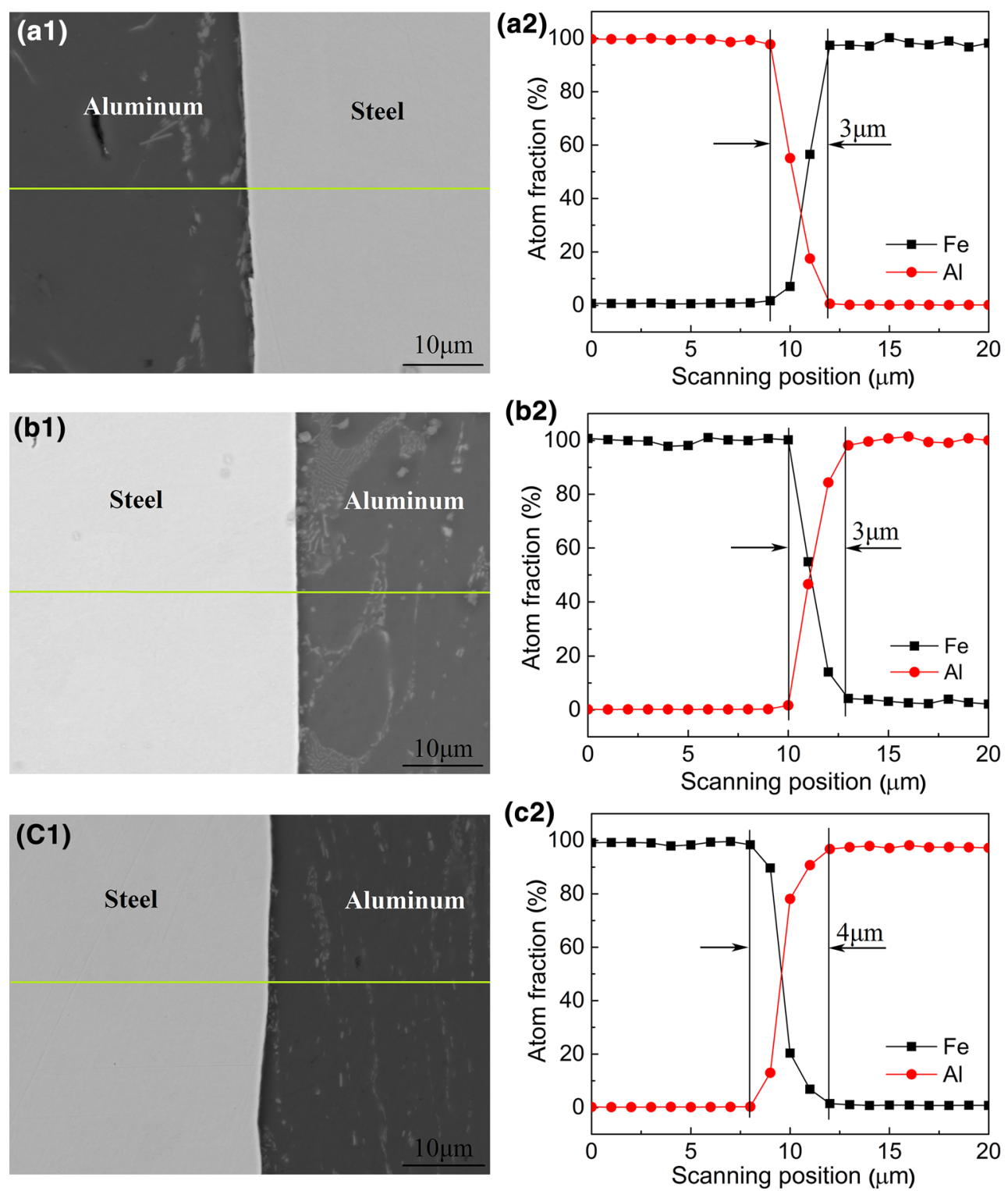

Fig. 5 Contents of $\mathrm{Fe}$ and $\mathrm{Al}$ across the bonding interface in a non-field [16], b ECP, c SMF+ECP clad sheets

effect [18]. The larger the inter-diffusion zone, the greater the strengthening effect, and this can also help explain the bonding strength increment by SMF+ECP.

Also notice that some intergranular phases appear in the back-scattered images in EPMA in Fig. 5. The as-cast sheet produced by twin-roll casting mainly consists of columnar dendrites and equiaxed dendrites [15]. At the boundaries of the dendrite arms, eutectic phases containing $\mathrm{Fe}$ and $\mathrm{Si}$ would form, which indicates the size of the arms. In the SMF+ECP sheet, the arm size is somewhat smaller than that in the non-field and ECP sheets. This happens as a result of the oscillating effect of the Lorentz force on the growing dendrites during solidification, which causes the dendrite arm smash into small pieces and the element content inside the dendrite arms increases.

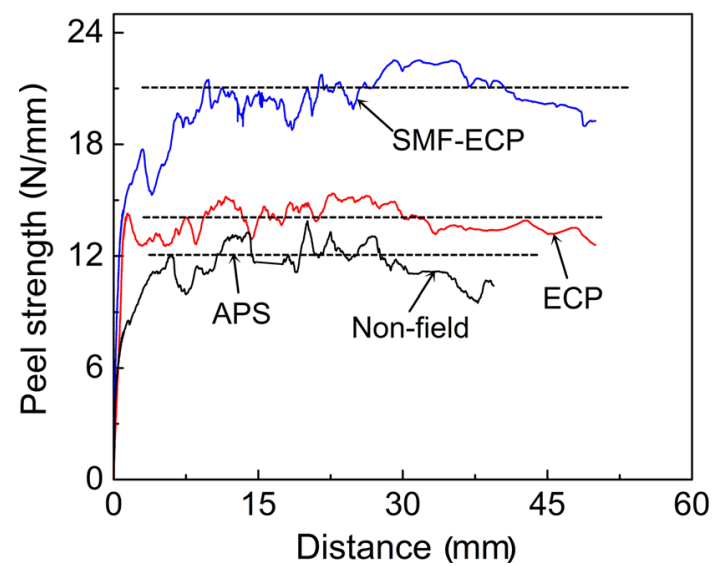

Fig. 6 Peel strength curves of the non-field, ECP and SMF+ECP clad sheets 

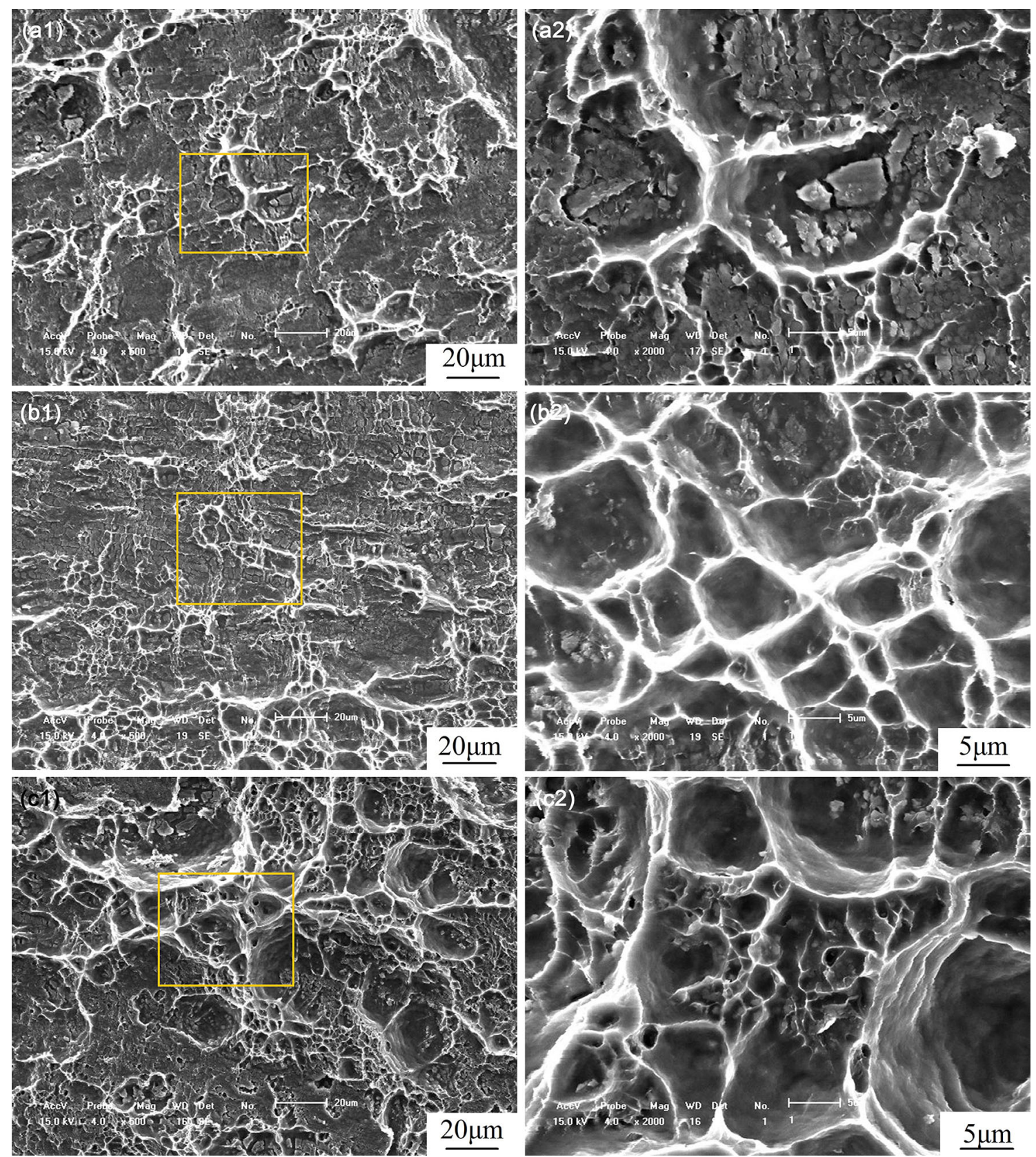

Fig. 7 Aluminum surfaces of a non-field [16], b ECP, c SMF+ECP clad sheet after peeling, an enlarged picture of the boxes on the left side shown on the right

\section{Conclusions}

1. Steel/aluminum clad sheets were successfully fabricated by horizontal twin-roll casting technique under electric current pulse (ECP) and complex field of static magnetic field and electric current pulse (SMF+ECP). The application of ECP or SMF+ECP increases the bonding strength of steel/aluminum interface by 17 and $75 \%$ compared with that of non-field clad sheet.
2. The electromagnetic body force generated by simultaneously applying SMF and ECP is bigger than the pulse electromagnetic force generated by applying ECP. So, SMF+ECP treatment can generate more bonding points and accelerate the diffusional layer width and then result in the highest bonding strength.

Acknowledgements This work was supported by the Industry-Academia-Research projects of Guangdong province, P. R. China (Grant Nos. 2014B090903012, 2013B090200008 and 2013B090600015). 


\section{References}

[1] A. Tripathi, I. Samajdar, J.F. Nie, A. Tewari, Mater. Charact. 114, 157 (2016)

[2] J.T. Li, G.M. Xu, H.L. Yu, G. Chen, H.J. Li, C. Lu, J.Y. Guo, Int. J. Adv. Manuf. Technol. 85, 1007 (2016)

[3] H.B. Wang, L. Zhou, Y.W. Zhang, Y.H. Cai, J.S. Zhang, J. Mater. Process. Technol. 233, 186 (2016)

[4] M. Slapakova, M. Zimina, S. Zaunschirm, J. Kastner, J. Bajer, M. Cieslar, Mater. Charact. 118, 44 (2016)

[5] H.Y. Ning, Y.D. Yu, K. Lin, L.H. Wen, C.X. Liu, J. Mater. Eng. Perform. 25, 635 (2016)

[6] T. Haga, S. Suzuki, J. Mater. Process. Technol. 138, 366 (2003)

[7] J.H. Bae, A.K. Prasada Rao, K.H. Kim, Nack J. Kim, Scr. Mater. 64, 836 (2011)

[8] M. Vidoni, R. Ackermann, S. Richter, G. Hirt, Adv. Eng. Mater. 17, 1588 (2015)

[9] O. Grydin, G. Gerstein, F. Nurnberger, M. Schaper, V. Danchenko, J. Manuf. Process. 15, 501 (2013)
[10] X.L. Liao, Q.J. Zhai, J. Luo, W.J. Chen, Y.Y. Gong, Acta Mater. $\mathbf{5 5}, 3103$ (2007)

[11] J.H. Ma, J. Li, Y.L. Gao, Q.J. Zhai, Mater. Lett. 63, 142 (2009)

[12] D. Rabiger, Y.H. Zhang, V. Galindo, S. Franke, B. Willers, S. Eckert, Acta Mater. 79, 317 (2014)

[13] C.J. Song, Y.Y. Guo, Y.H. Zhang, H.X. Zheng, M. Yan, Q.Y. Han, Q.J. Zhai, J. Cryst. Growth 324, 235 (2011)

[14] Y.H. Zhang, C.J. Song, L. Zhu, H.X. Zheng, H.G. Zhong, Q.Y. Han, Q.J. Zhai, Metall. Mater. Trans. B 42, 604 (2011)

[15] X. Su, S.J. Wang, X. OuYang, P. Song, G.M. Xu, D.H. Jiang, Mater. Sci. Eng. A 607, 10 (2014)

[16] G. Chen, J.T. Li, H.L. Yu, L.H. Su, G.M. Xu, J.S. Pan, T. You, G. Zhang, K.M. Sun, L.Z. He, Mater. Des. 112, 263 (2016)

[17] M. Eizadjou, H. Danesh Manesh, K. Janghorban, Mater. Des. 29, 909 (2008)

[18] T. Liu, Q.D. Wang, Y.D. Sui, Q.G. Wang, W.J. Ding, Mater. Des. 68, 8-17 (2015) 